\title{
Permethylation and Microfractionation of Sulfated Glycans for MS Analysis
}

\author{
Shin-Yi Yu ${ }^{1,2, *}$, Sergei Snovida ${ }^{1, \$}$ and Kay-Hooi Khoo ${ }^{1}$ \\ ${ }^{1}$ Institute of Biological Chemistry, Academia Sinica, Nankang, Taipei 115, Taiwan \\ ${ }^{2}$ University Lille, CNRS, UMR 8576 -UGSF- Unité de Glycobiologie Structurale et Fonctionnelle, 59000 Lille, France \\ ${ }^{\$ C}$ Current/Present address: Thermo Fisher Scientific, Rockford, Illinois 61101, United States \\ *For correspondence: shinyi.yu@univ-lille.fr
}

\begin{abstract}
Sulfated glycans are barely detectable in routine mass spectrometry (MS)-based glycomic analysis due to ion suppression by the significantly more abundant neutral glycans in the positive ion mode, and sialylated non-sulfated glycans in the negative ion mode, respectively. Nevertheless, the negative charge imparted by sulfate can be advantageous for selective detection in the negative ion mode if the sialic acids can first be neutralized. This is most conveniently achieved by a concerted sample preparation workflow in which permethylation is followed by solid phase fractionation to isolate the sulfated glycans prior to MS analysis. Importantly, we demonstrated that conventional $\mathrm{NaOH} / \mathrm{DMSO}$ slurry permethylation method can retain the sulfates. Instead of extracting permethylated glycans into chloroform for sample clean-up, reverse phase C18 cartridge coupled with self-packed amine-tip or mixed mode weak anion exchange cartridge can be utilized to obtain in good yield the non-sulfated, mono-sulfated, and multiply sulfated permethylated glycans in separate fractions for sulfoglycomic analysis.
\end{abstract}

Keywords: Permethylated sulfated glycans, Sulfoglycomics, Mass spectrometry, Glycan fractionation, Reverse phase (C18) cartridge, Amine-tip, Mixed mode weak anion exchange (MAX) cartridge

This protocol was validated in: J Biol Chem (2018), DOI: 10.1074/jbc.RA118.001937 


\section{Background}

Sulfated glycans carrying sulfo sialyl LeX glycotope are ligands of L-selectin involved in lymphocyte homing in physiological and inflammatory states (Rosen, 2004; Kawashima, 2006). Many glycan array studies also showed that sulfated glycotopes are better ligands of several galectins (Ideo et al., 2002) and Siglecs (Bochner et al., 2005). However, there is very limited knowledge of endogenous sulfated glycans expressed on different types of mammalian cells, tissues or organism due to their low abundance and availability of few well-defined antibodies. Advanced mass spectrometry (MS)-based analysis is the only viable technique that would afford the requisite high sensitivity and accuracy for a meaningful probing of the cellular sulfoglycome.

Sulfated glycans are not readily detected in the conventional MS-based glycomic profiling. For analysis of nonderivatized, native sulfated glycans in the negative ion mode, the main problem is that sialylated glycans also carry negative charges and these are usually more abundant. Removing the sialic acids by treatment with sialidase is commonly applied (Hernandez Mir et al., 2009), but information on the sulfated sialylated glycans, which maybe the true physiological ligands for endogenous lectins is lost. For permethylated glycans, the advantages are neutralization of the negative charge of sialic acid and more reliable, sequence informative fragment ions can be obtained by MS/MS analyses. A precondition though is that the widely used sample clean-up method following permethylation, such as extraction by chloroform/water partition, which would result in loss of permethylated sulfated glycans into the aqueous layer, should be avoided (Morelle and Michalski, 2007; Kumagai et al., 2013).

We have shown that the conventional $\mathrm{NaOH} / \mathrm{DMSO}$ slurry permethylation can retain the sulfates, and reverse phase (C18) solid phase extraction cartridge can be used to replace chloroform extraction (Yu et al., 2009; Khoo and $\mathrm{Yu}, 2010)$. Both permethylated non-sulfated and sulfated glycans are retained, extensively washed, and then eluted without introducing salts. MALDI-MS screening of permethylated glycans in the negative ion mode gives a quick survey for the presence of sulfated glycans. Instead of using 2,5 dihydroxybenzoic acid (DHB), which is a common matrix for glycan analysis in the positive ion mode (Harvey, 1993), we found that 3,4diaminobenzophenone (DABP) afforded a better sensitivity for detecting permethylated sulfated glycans in the negative ion mode. Non-sulfated, mono-sulfated, di-sulfated permethylated glycans can be further fractionated by using a self-packed amine tip. Alternatively, a mixed mode weak anion exchange (MAX) cartridge containing both reverse phase and weak anion exchange properties can be used to replace the two-step process of cleaning and fractionation (Cheng et al., 2013; Cheng et al., 2015; Hsiao et al., 2017). The developed workflow for sulfoglycomics (Figure 1) has been successfully applied to many different biological samples such as lymph nodes from different glycosyltransferase/sulfotransferase knockout mice (Mitoma et al., 2007; Patnode et al., 2013), ovarian cancer (Shibata et al., 2012; Yu et al., 2013), colon cancer (Yu et al., 2018), immune cells (Patnode et al., 2013; Wang et al., 2013). Collectively, it showed that sulfated $N$ - and $O$-glycans have a wider and ubiquitous occurrence than previously appreciated.

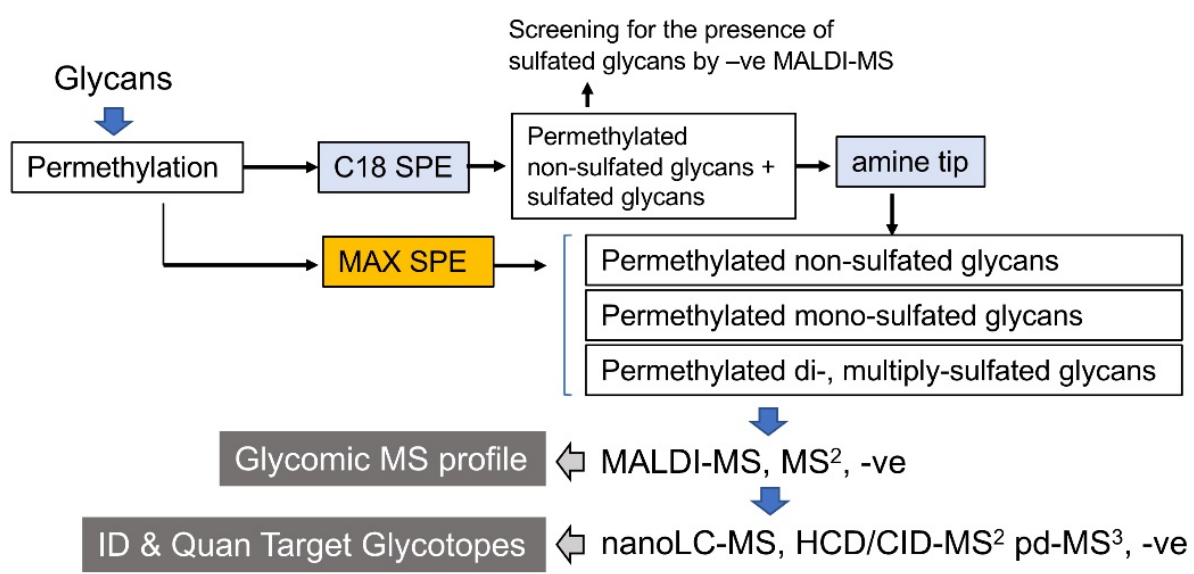

Figure 1. Schematic workflow for MS-based sulfoglycomic analyses.

The key steps are reverse phase C18 which retains all permethylated glycans, and further fractionation of 
sulfated permethylated glycans from non-sulfated ones by amine beads. Alternatively, a mixed mode anion exchange (MAX) SPE is equally effective. MALDI-MS screening in the negative ion mode affords a quick profile of the sulfoglycome. This protocol is applicable to all commonly found sulfated $\mathrm{N}$-glycans and $\mathrm{O}$ glycans, irrespective of their reducing end status. The procedure for additional nanoLC-nanoESI-MS/MS analyses was described in another paper entitled "Negative Ion Mode nanoLC-ESI-MS/MS Analyses of Permethylated Sulfated Glycans” in Bio-protocol (Yu et al., 2020). SPE, solid phase extraction.

\section{Materials and Reagents}

1. C18 cartridge (Waters, Sep-Pak, catalog number: WAT091139)

2. ZipTipC 18 (Merck Millipore, catalog number: ZTC18S096)

3. NUCLEOSIL ${ }^{\circledR} 100-5 \mathrm{NH}_{2}$ (MACHEREY-NAGEL, Nucleosil, catalog number: 712200.10)

4. Disposable $20 \mathrm{ml}$ Syringe (BD, catalog number: 300296)

5. Filter paper

6. $\quad$ Oasis MAX 3 сc Vac Cartridge (Waters, Oasis, catalog number: 186000367)

7. Several clear chemical glass bottles, 250 ml (PYREX ${ }^{\circledR}$, catalog number: 1515-06D), 500 ml (PYREX ${ }^{\circledR}$, catalog number: 1515-08D)

8. $\quad$ PYREX ${ }^{\circledR} 13$ x $100 \mathrm{~mm}$ round bottom glass tubes (Corning, catalog number: 99449-13)

9. Corning ${ }^{\circledR}$ Reusable Phenolic GPI 13-415 screw cap with PTFE Liner (Corning, catalog number: 9998-13)

10. Glass Pasteur pipette (Corning, catalog number: 7095B-9) and plastic pipette tips

11. $\mathrm{pH}$-indicator strips $\mathrm{pH}$ 0-14 Universal indicator (Merck Millipore, catalog number: 1.09535.0001)

12. $1.5 \mathrm{ml}$ Eppendorf safe-lock tubes (Eppendorf, catalog number: 0030120086)

13. Sodium hydroxide (NaOH) (Merck Millipore, catalog number: 106498)

14. Dimethyl sulfoxide (DMSO) (Merck Millipore, catalog number: 1029310161)

15. Methyl iodide (stabilized with silver) (Merck Millipore, catalog number: 806064)

16. $100 \%$ ethanoic acid (glacial) (Merck Millipore)

17. Acetonitrile (ACN) (VWR chemicals, catalog number: 20060.320)

18. Methanol (VWR chemicals, catalog number: BDH1135-1LP)

19. 3,4-diaminobenzophenone (DABP) (Acros Organics ${ }^{\mathrm{TM}}$, catalog number: 184800250)

20. Ammonium acetate $\left(\mathrm{NH}_{4} \mathrm{OAc}\right)$ (Sigma Aldrich, catalog number: 5.43834$)$

21. Trifluoroacetic acid (TFA) (Sigma-Aldrich, catalog number: $302031-100 \mathrm{~m}$ ), store in $4{ }^{\circ} \mathrm{C}$

22. Formic acid (FA) (Merck Millipore, catalog number: 5.438040.100)

23. $2.5 \% \mathrm{ACN}(200 \mathrm{ml})$ (see Recipes)

24. $10 \%$ ACN $(200 \mathrm{ml})$ (see Recipes)

25. $25 \%$ ACN (200 ml) (see Recipes)

26. $50 \%$ ACN (200 ml) (see Recipes)

27. $0.1 \%$ TFA $(50 \mathrm{ml})$ (see Recipes)

28. $75 \%$ ACN, $0.1 \%$ TFA (50 ml) (see Recipes)

29. $95 \% \mathrm{ACN}(50 \mathrm{ml})$ (see Recipes)

30. $95 \%$ ACN, $0.1 \%$ FA (50 ml) (see Recipes)

31. $50 \%$ ACN, $0.1 \%$ FA (50 ml) (see Recipes)

32. $1 \mathrm{M}$ ammonium acetate $\left(\mathrm{NH}_{4} \mathrm{OAc}\right)$ (see Recipes)

33. $50 \%$ ACN, $2.5 \mathrm{mM} \mathrm{NH}_{4} \mathrm{OAc}(50 \mathrm{ml}$ ) (see Recipes)

34. $50 \% \mathrm{ACN}, 10 \mathrm{mM} \mathrm{NH}_{4} \mathrm{OAc}(50 \mathrm{ml})$ (see Recipes)

35. $100 \mathrm{mM} \mathrm{NH}_{4} \mathrm{OAc}(200 \mathrm{ml})$ (see Recipes)

36. $80 \%$ ACN, $1 \mathrm{mM} \mathrm{NH} 4 \mathrm{OAc}$ (200 ml) (see Recipes)

37. $60 \%$ ACN, $20 \%$ methanol, $100 \mathrm{mM} \mathrm{NH}_{4} \mathrm{OAc}$ (200 ml) (see Recipes) 


\section{Equipment}

1. Ceramic mortar and pestle

2. Laboratory fume hood

3. $50^{\circ} \mathrm{C}$ heater

4. Vortex-Genie ${ }^{\circledR} 2$ (Scientific Industries) coupled with 9-16 mm foam inserts (Scientific Industries, model: 5030278-00)

5. Savant SpeedVac ${ }^{\circledR}$ concentrator (Thermo Scientific, model: ISS110) with rotor (Thermo Scientific, catalog number: RH20-12)

6. MALDI-TOFTOF 4700 Proteomics Analyzer or any equivalent MALDI-TOFTOF series (Applied Biosystems, Sciex) mass spectrometer

\section{Software}

1. Data Explorer version 4.5 (Applied Biosystems)

\section{Procedure}

\section{A. Permethylation of glycans}

1. Any glycan of reasonable size including the normal range of mammalian $N$ - and $O$-glycans prepared from glycoprotein(s), cells, tissues and organs using the conventional protocols (Jang-Lee et al., 2006; Morelle and Michalski, 2007), with free or reduced reducing ends depending on the glycan release methods, can be subjected to the permethylation and sample clean-up/ microfractionation protocols described here. Heavily sulfated glycosaminoglycan fragments have not been tested but 50 pmole starting material of tetrasulfated diLacNAc tetrasaccharides

could be efficiently permethylated, retained by SepPakC18, and successfully detected by subsequent MALDI-MS analysis (Yu et al., 2009).

2. Aliquot the suitably prepared glycan sample (in Milli-Q water) into a 13 x $100 \mathrm{~mm}$ glass tube.

3. Dry the glycans by SpeedVac.

4. Add $5 \mathrm{ml}$ of DMSO into mortar followed by $5 \mathrm{NaOH}$ pellets. Grind the $\mathrm{NaOH}$ pellets to a slurry by the use of a pestle.

5. Add $0.2 \mathrm{ml}$ of the $\mathrm{NaOH} / \mathrm{DMSO}$ slurry into glass tube containing glycans, followed by the addition of 0.1 $\mathrm{ml}$ of methyl iodide. Perform this step in the laboratory fume hood.

6. Put the sample onto vortex mixer and vortex gently for $3 \mathrm{~h}$, at $4{ }^{\circ} \mathrm{C}$

7. Add dropwise $0.2 \mathrm{ml}$ of cold Milli-Q water into glass tube directly to quench the reaction, followed by careful neutralization with several drops of $5 \%$ aqueous acetic acid. Check the $\mathrm{pH}$ value of sample until pH 5-8 by pH indicator strips. Remove methyl iodide by putting samples under a stream of nitrogen in the fume hood.

Note: The neutralized reaction mix can be loaded into Oasis ${ }^{\circledR}$ MAX cartridge directly (see Procedure E).

\section{B. Clean-up permethylated glycans by Sep-Pak C18}

1. Equilibrate C18 Sep-Pak cartridge by $3 \mathrm{ml}$ of $100 \% \mathrm{ACN}, 3 \mathrm{ml}$ of methanol, $3 \mathrm{ml}$ of water sequentially.

2. Transfer the neutralized reaction mixture into the primed C18 Sep-Pak cartridge.

3. Wash cartridge with $5 \mathrm{ml}$ of water, $5 \mathrm{ml}$ of $2.5 \%$ ACN, and $10 \%$ ACN subsequently to remove hydrophilic salts and contaminants.

4. Elute permethylated glycans by $3 \mathrm{ml}$ of $25 \% \mathrm{ACN}$, followed by $3 \mathrm{ml}$ of $50 \%$ ACN into the same tube. 
Notes:

a. Di-sulfated permethylated N-glycans will be collected in the 25\% ACN fraction, and mono-sulfated along with non-sulfated permethylated N-glycans will be eluted in $50 \%$ ACN fraction.

b. For O-glycans, di-sulfated, mono-sulfated, part of smaller non-sulfated permethylated O-glycans will normally be found in 25\% ACN fraction, whereas larger mono-sulfated permethylated O-glycans and larger non-sulfated O-glycans will be collected in 50\% ACN fraction.

5. Dry samples by SpeedVac

\section{Screen permethylated sulfated glycans by MALDI-MS in negative ion mode}

1. Prepare $10 \mathrm{mg} / \mathrm{ml}$ of 3,4-diaminobenzophenone in 75\% ACN, 0.1\% TFA in a $1.5 \mathrm{ml}$ Eppendorf tube.

2. Dissolve the permethylated glycan samples in 20-50 $\mu \mathrm{l}$ of ACN.

Note: The volume of ACN to dissolve the sample highly depends on the amount of glycans. If the quantity is unclear, 20-50 $\mu \mathrm{l}$ of ACN is a good starting volume.

3. Take $0.5 \mu \mathrm{l}$ of sample and mix well with $0.5 \mu \mathrm{l}$ of 3,4-DABP as matrix in an Eppendorf tube.

4. Spot the mixed sample onto the MALDI target plate above a $50{ }^{\circ} \mathrm{C}$ heater.

5. Acquire MS data in the negative ion mode, reflector mode.

a. MS data was acquired under either manual or automated target movement depending on the state of crystallization

b. The laser energy set for 3,4-DABP is similar to that for 2,5-DHB. In our 4700 Proteomics Analyzer and experience on 4800 Plus MALDI TOF/TOF Analyzer, the laser energy is set to around 4,5005,000. Laser Nd-YAG $200 \mathrm{~Hz}$ is used.

c. A typical acquisition comprises a total of 20 sub-spectra with 50 laser shots per sub-spectrum.

\section{Separation of sulfated permethylated glycans from non-sulfated ones by amine tip}

1. Prepare self-packed amine tip.

a. Take a $200 \mu \mathrm{l}$ yellow pipette tip and plug its tapered end with filter paper $(0.1 \mathrm{~cm} \mathrm{x} 0.1 \mathrm{~cm}$ size $)$ by the use of $5 \mathrm{~cm}$ length needle or any equivalent tool (as shown in Figure 2A).

b. Take up the amine beads in methanol, and pack them into the yellow tip. The volume of the packed beads in yellow pipette tip is normally $20 \mu \mathrm{l}$.

c. Use the plunger of a $20 \mathrm{ml}$ syringe (Figure $2 \mathrm{~B}$ ) to gently apply pressure to wash out the methanol (Figure 2C). Do not completely dry out the self-packed amine tip.

2. Equilibrate the packed amine tip by adding $100 \mu \mathrm{l}$ of $100 \% \mathrm{ACN}$ and again use the $20 \mathrm{ml}$ syringe plunger to apply pressure to push out the solvent. Follow with another $100 \mu \mathrm{l}$ of $95 \%$ ACN with $0.1 \%$ FA and 100 $\mu \mathrm{l}$ of $50 \%$ ACN with $0.1 \%$ FA, and $100 \mu \mathrm{l}$ of $95 \%$ ACN with $0.1 \%$ FA, sequentially.

3. Dissolve the permethylated glycans from Step B5 in 20-50 $\mu$ l of $100 \%$ ACN.

4. Load the permethylated glycans onto self-packed amine tip and collect the flow through in the Eppendorf tube.

5. Reload the collected flow through sample onto tip, and collect the flow through in the new Eppendorf tube.

6. Wash the tip with $100 \mu \mathrm{l}$ of $95 \%$ ACN. Collect the flow through and wash fractions in the same Eppendorf tube. This tube contains non-sulfated permethylated glycans.

7. Elute mono-sulfated permethylated glycans with $100 \mu \mathrm{l}$ of $2.5 \mathrm{mM} \mathrm{NH} 4 \mathrm{OAc}$ in $50 \% \mathrm{ACN}$, and collect the eluent in the new Eppendorf tube.

8. Elute di-sulfated permethylated glycans with $100 \mu \mathrm{l}$ of $10 \mathrm{mM} \mathrm{NH} 4 \mathrm{OAc}$ in $50 \% \mathrm{ACN}$, and collect the eluent in the new Eppendorf tube.

9. Screen samples by MALDI-MS in the negative ion mode (the same as Procedure C). 

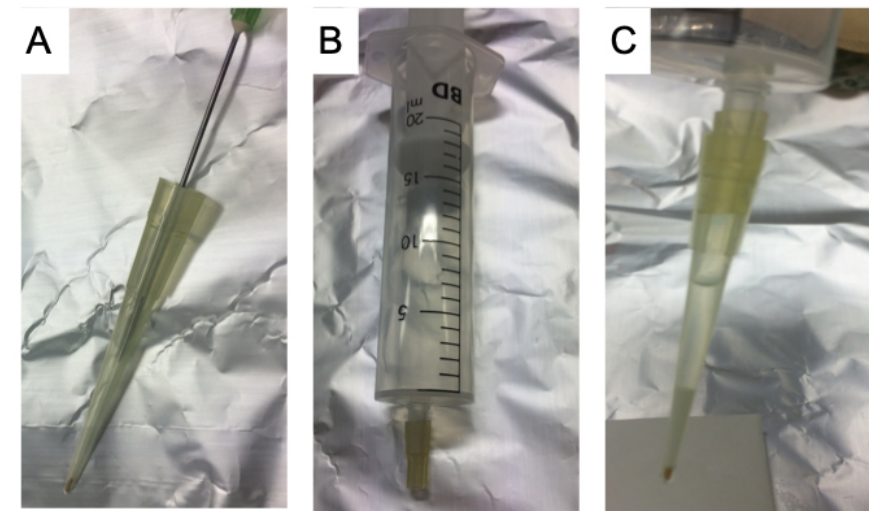

Figure 2. The demonstration how to make self-packed amine tip.

Step 1. Plug the yellow tip with filter paper by needle (shown in A). Step 2. Use $20 \mathrm{ml}$ syringe as a plunger and put on a plastic hose on syringe to fit with yellow tip (shown in B). Step 3. Pack amine beads into the yellow tip by using syringe to wash out the solvent (shown in C).

\section{E. Separation of sulfated permethylated glycans from non-sulfated ones by Oasis ${ }^{\circledR}$ MAX}

1. Equilibrate an Oasis ${ }^{\circledR}$ MAX cartridge with $3 \mathrm{ml}$ of $95 \%$ ACN and $3 \mathrm{ml}$ of $100 \mathrm{mM} \mathrm{NH}_{4} \mathrm{OAc}$.

2. Add $1 \mathrm{ml}$ of $100 \mathrm{mM} \mathrm{NH}_{4} \mathrm{OAc}$ into the cartridge and load the neutralized reaction mixtures (Procedure $\mathrm{A}$ ) and collect all the unbound samples in one glass tube. Reload the unbound fraction into the MAX cartridge.

3. Wash the cartridge by $1 \mathrm{ml}$ of $100 \mathrm{mM}$ ammonium acetate, followed by $6 \mathrm{ml}$ of water to remove as much salts as possible.

4. Elute the non-sulfated permethylated glycans by $6 \mathrm{ml}$ of $95 \% \mathrm{ACN}$, and collect the eluent in the new glass tube.

5. Elute the mono-sulfated permthylated glycans by $6 \mathrm{ml}$ of $1 \mathrm{mM} \mathrm{NH} \mathrm{m}_{4} \mathrm{OAc}$ in $80 \% \mathrm{ACN}$, and collect the eluent in the new glass tube.

6. Elute permethylated glycans with more than one sulfate by $3 \mathrm{ml}$ of $100 \mathrm{mM} \mathrm{NH}_{4} \mathrm{OAc}$ in $60 \% \mathrm{ACN}, 20 \%$ methanol, and collect the eluent in the new glass tube.

7. $\quad$ Dry samples by SpeedVac

Note: This mixed mode cartridge allows direct cleanup and sequential fractionation into non-sulfated, and sulfated glycans in one step.

\section{F. Further clean-up of permethylated glycans or concentration by ZipTipC $\mathrm{C}_{18}$}

1. Transfer permethylated glycans (in ACN) into $0.5 \mathrm{ml}$ or $1.5 \mathrm{ml}$ Eppendorf tube and dry.

2. Dissolve permethylated glycans in $20 \mu \mathrm{l}$ of $10 \%$ ACN.

Note: To have better solubility of permethylated glycans in 10\% ACN, use $2 \mu \mathrm{l}$ of $100 \%$ ACN to re-dissolve and sequentially add $18 \mu$ l of water while constantly vortex the tube.

3. Equilibrate ZipTipC 18 by $10 \mu \mathrm{l}$ of $50 \%$ ACN, $0.1 \%$ TFA, then $10 \mu \mathrm{l}$ of $0.1 \%$ TFA.

4. Load sample by pipetting several times.

5. Wash ZipTipC 18 by $10 \mu$ l of $0.1 \%$ TFA, three times.

6. Elute the glycans by $10 \mu \mathrm{l}$ of $50 \%$ ACN, $0.1 \%$ TFA, or less volume, for collection into microtubes or direct spotting with matrix onto the MALDI target plate, followed by MS acquisition (Procedure C).

\section{Data analysis}

1. All the MALDI-MS data are manually interpreted. In mammalian glycosylation, the common glycosyl residues

Cite as: Yu, S. Y. et al. (2020). Permethylation and Microfractionation of Sulfated Glycans for MS Analysis. Bio-protocol 10(10): e3617. DOI: 10.21769/BioProtoc.3617. 
are Hex, HexNAc, dHex (Fuc), Neu5Ac, and Neu5Gc, and the nominal masses of the permethylated forms are 204, 245, 174, 361, and $391 \mathrm{u}$, respectively. The accurate monoisotopic and average mass of different monosaccharide forms can be readily calculated or referring to Table I in Dell et al. (1994). For MALDI-MS of permethylated glycans in the negative ion mode, non-sulfated permethylated glycans do not normally afford any negative ion signal since all hydroxyl $(\mathrm{OH})$ groups have been derivatized to $O$-methyl (OMe), and the carboxylic $(\mathrm{COOH})$ group of sialic acids to methyl esters (COOMe).

2. To calculate the singly charged $\mathrm{m} / \mathrm{z}$ values of sulfated permethylated glycans in the negative ion mode, use the general formula:

a. Mono-sulfated permethylated glycans, detected as [M-H]

$m / z=\left(\mathrm{CH}_{3}+\mathrm{OCH}_{3}\right)+\Sigma$ glycosyl residue masses $+\left(\mathrm{OSO}_{3}{ }^{-}-\mathrm{OCH}_{3}\right)$

b. Di-sulfated permethylated glycans, detected as $[\mathrm{M}+\mathrm{Na}-2 \mathrm{H}]^{-}$

$m / z=\left(\mathrm{CH}_{3}+\mathrm{OCH}_{3}\right)+\Sigma$ glycosyl residue masses $+2 \mathrm{x}\left(\mathrm{OSO}_{3}{ }^{-}-\mathrm{OCH}_{3}\right)+23$

$\left(\mathrm{CH}_{3}+\mathrm{OCH}_{3}\right)$ corresponds to the respective non-reducing and reducing end masses, which is $46 \mathrm{u}$ in nominal mass. For the $O$-glycans that were released from glycoproteins via reductive elimination, as well as any other pre-reduced $N$-glycans, their reducing end would be in an alditol state (annotated as -itol), and the corresponding nominal mass would be $62 \mathrm{u}$. $\left(\mathrm{OSO}_{3}{ }^{-}-\mathrm{OCH}_{3}\right)$ refers to the first sulfate carried, which corresponds to a 65 u mass increment, and contributing to the negative charge. Thereafter, for di- and multiply sulfated glycans, each additional sulfate group contributes to $88 \mathrm{u}(65+23 \mathrm{u})$ mass increment from the mono-sulfated glycan due to the charge of second sulfate being counter balanced by a sodium. For examples in Figure 3, the $[\mathrm{M}-\mathrm{H}]^{-}$molecular ion signal at $\mathrm{m} / \mathrm{z} 1386$ for a mono-sulfated $\mathrm{NeuAc}_{1} \mathrm{Hex}_{2} \mathrm{HexNAc}_{2}$-itol corresponds to [62 + $361+204$ x $2+245$ x $\left.2+65\right]$, whereas the [M+Na-2H] ${ }^{-}$ molecular ion signal at $m / z 1562$ for a di-sulfated $\mathrm{Hex}_{3} \mathrm{HexNAc}_{3}$-itol corresponds to [62 $+204 \times 3+245$ $\mathrm{x} 3+65+88]$.

3. The signal corresponding to loss of sodium sulfite $\left(-102 \mathrm{u}, \mathrm{NaSO}_{3}\right)$ from di- and multiply sulfated glycans during MALDI ionization are often produced easily. Sometimes only these and not the ones retaining all sulfates were detected. It is also equivalent in mass to $-14 \mathrm{u}$ from the mono-sulfated species, and overlaps with any undermethylated form, if present (as shown in Figure 1.3A in Khoo and Yu (2010)).

Note: In practice, the relative signal intensity of monosodiated, di-sulfated permethylated glycans and those having lost the extra sodium sulfite varies from sample to sample and also somewhat depends on the MALDIMS instrument conditions. In the case example shown in Figure 3B, the intensity of the di-sulfated O-glycan ion signal at m/z 1562 is much stronger than the signal at m/z 1460, but the reverse pattern has also been observed in other samples.
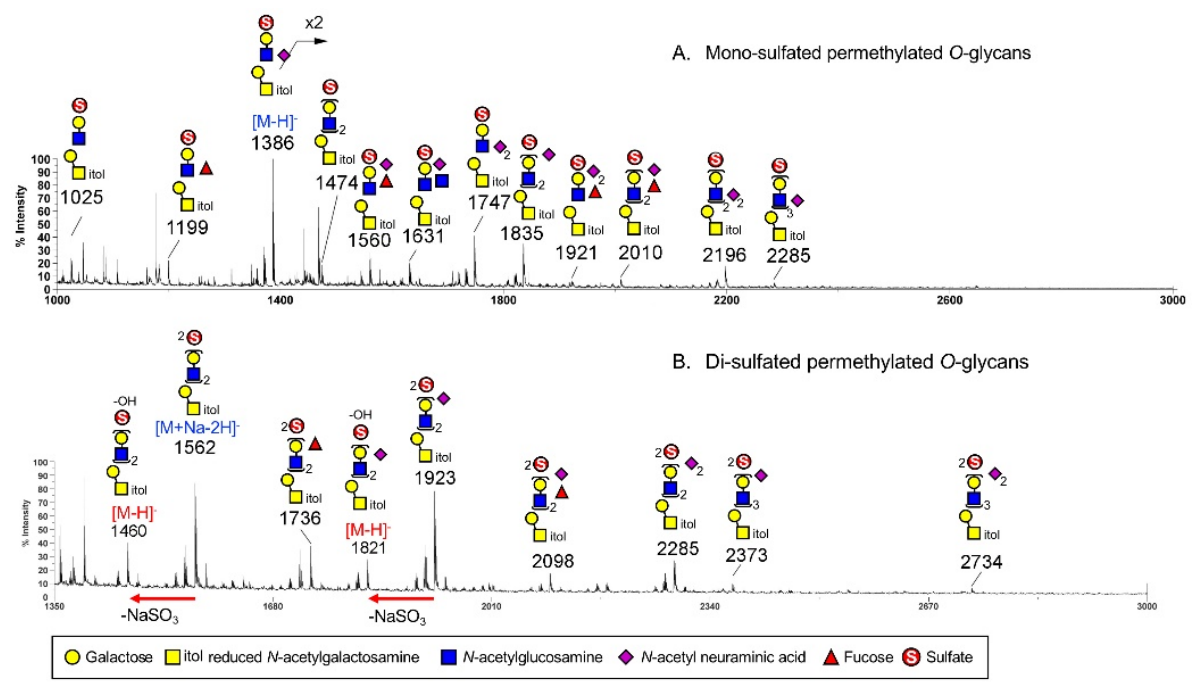

Figure 3. MALDI-MS profiles of mono-sulfated (A) and di-sulfated (B) permethylated $O$-glycans in the negative ion mode.

Cite as: Yu, S. Y. et al. (2020). Permethylation and Microfractionation of Sulfated Glycans for MS Analysis. Bio-protocol 10(10): e3617. DOI: 10.21769/BioProtoc.3617. 
The mono-sulfated and di-sulfated permethylated O-glycans were separated into different fractions by aminebeads, using the protocol described here. The mono-sulfated $O$-glycans were eluted in the earlier $2.5 \mathrm{mM}$ $\mathrm{NH}_{4} \mathrm{OAc}$ in $50 \%$ ACN fraction (A) whereas the di-sulfated $O$-glycans in the $10 \mathrm{mM} \mathrm{NH} 4 \mathrm{OAc}$ in $50 \%$ ACN fraction (B). The $O$-glycans shown here were reductively released from colonic cancer cell line SW480 transfected with GlcNAc6ST-2, as described in details in the original report (Yu et al., 2018).

\section{Notes}

The non-sulfated, sialylated glycans will co-elute with the sulfated glycans and be detected in the negative ion mode if the carboxylic group of their sialic acid remain non-methyl-esterified during the permethylation process. This undermethylation issue can be solved by re-permethylation of the recovered glycans. A prior clean-up of the native glycans by graphitized carbon column before permethylation may help achieving full permethylation. The detailed protocol was described in Khoo and Yu (2010).

\section{Recipes}

\section{1. $2.5 \%$ ACN $(200 \mathrm{ml})$}

$5 \mathrm{ml}$ of $100 \%$ ACN

$195 \mathrm{ml}$ of $\mathrm{ddH}_{2} \mathrm{O}$

2. $10 \%$ ACN $(200 \mathrm{ml})$

$20 \mathrm{ml}$ of $100 \%$ ACN

$180 \mathrm{ml}$ of $\mathrm{ddH}_{2} \mathrm{O}$

3. $25 \%$ ACN (200 ml)

$50 \mathrm{ml}$ of $100 \%$ ACN

$150 \mathrm{ml}$ of $\mathrm{ddH}_{2} \mathrm{O}$

4. $50 \%$ ACN (200 ml)

$100 \mathrm{ml}$ of $100 \% \mathrm{ACN}$

$100 \mathrm{ml}$ of $\mathrm{ddH}_{2} \mathrm{O}$

5. $0.1 \%$ TFA $(50 \mathrm{ml})$

$50 \mu \mathrm{l}$ of TFA in $49.95 \mathrm{ml}$ of $\mathrm{ddH}_{2} \mathrm{O}$

6. $75 \%$ ACN, $0.1 \%$ TFA (50 ml)

$37.5 \mathrm{ml}$ of $100 \%$ ACN

$12.45 \mathrm{ml}$ of $\mathrm{ddH}_{2} \mathrm{O}$

$50 \mu \mathrm{l}$ of TFA

7. $95 \%$ ACN (50 ml)

$47.5 \mathrm{ml}$ of $100 \%$ ACN

$2.5 \mathrm{ml}$ of $\mathrm{ddH}_{2} \mathrm{O}$

\section{8. $95 \%$ ACN, $0.1 \%$ FA $(50 \mathrm{ml})$}

$47.5 \mathrm{ml}$ of $100 \%$ ACN

$2.45 \mathrm{ml}$ of $\mathrm{ddH}_{2} \mathrm{O}$

$50 \mu \mathrm{l}$ of FA

Cite as: Yu, S. Y. et al. (2020). Permethylation and Microfractionation of Sulfated Glycans for MS Analysis. Bio-protocol 10(10): e3617. DOI: 10.21769/BioProtoc.3617. 
9. $50 \%$ ACN, $0.1 \%$ FA $(50 \mathrm{ml})$

$25 \mathrm{ml}$ of $100 \% \mathrm{ACN}$

$24.95 \mathrm{ml}$ of $\mathrm{ddH}_{2} \mathrm{O}$

$50 \mu \mathrm{l}$ of FA

10. $1 \mathrm{M}$ ammonium acetate (NH4OAc)

Prepare $100 \mathrm{ml}$ of $1 \mathrm{M}$ ammonium acetate $\left(\mathrm{NH}_{4} \mathrm{OAc}\right)$ in deionized water as stock solution:

$7.7 \mathrm{~g} \mathrm{NH}_{4} \mathrm{OAc}, 100 \mathrm{ml}$ of $\mathrm{ddH}_{2} \mathrm{O}$

11. $50 \%$ ACN, $2.5 \mathrm{mM}$ NH4OAc $(50 \mathrm{ml})$

$25 \mathrm{ml}$ of $100 \%$ ACN

$0.125 \mathrm{ml}$ of $1 \mathrm{M} \mathrm{NH}_{4} \mathrm{OAc}$

$24.875 \mathrm{ml}$ of $\mathrm{ddH}_{2} \mathrm{O}$

12. $50 \%$ ACN, $10 \mathrm{mM}$ NH4OAc $(50 \mathrm{ml})$

$25 \mathrm{ml}$ of $100 \%$ ACN

$0.5 \mathrm{ml}$ of $1 \mathrm{M} \mathrm{NH}_{4} \mathrm{OAc}$

$24.5 \mathrm{ml}$ of $\mathrm{ddH}_{2} \mathrm{O}$

13. $100 \mathrm{mM}$ NH4OAc $(200 \mathrm{ml})$

$20 \mathrm{ml}$ of $1 \mathrm{M} \mathrm{NH}_{4} \mathrm{OAc}$

$180 \mathrm{ml}$ of $\mathrm{ddH}_{2} \mathrm{O}$

14. $80 \%$ ACN, 1 mM NH4OAc $(200 \mathrm{ml})$

$160 \mathrm{ml}$ of $100 \%$ ACN

$0.2 \mathrm{ml}$ of $1 \mathrm{M} \mathrm{NH}_{4} \mathrm{OAc}$

$39.8 \mathrm{ml}$ of $\mathrm{ddH}_{2} \mathrm{O}$

15. $60 \%$ ACN, $20 \%$ methanol, $100 \mathrm{mM}$ NH4OAc $(200 \mathrm{ml})$

$120 \mathrm{ml}$ of $100 \%$ ACN

$40 \mathrm{ml}$ of methanol

$20 \mathrm{ml}$ of $1 \mathrm{M} \mathrm{NH}_{4} \mathrm{OAc}$

$20 \mathrm{ml}$ of $\mathrm{ddH}_{2} \mathrm{O}$

\section{Acknowledgments}

The sulfoglycomic workflow based on MALDI-MS analysis of permethylated glycans was originally developed by Yu et al. (2009), described in Khoo and Yu (2010), and further refined by introducing the MAX fractionation method, as described in Cheng et al. (2013). It was supported by Academia Sinica and Taiwan National Science Council grants to KKH and the NRPGM Core Facilities for Proteomics and Glycomics located at IBC, Academia Sinica.

\section{Competing interests}

The authors declare no conflicts of interest. 


\section{References}

Bochner, B. S., R. A. Alvarez, P. Mehta, N. V. Bovin, O. Blixt, J. R. White and R. L. Schnaar (2005). Glycan array screening reveals a candidate ligand for Siglec-8. J Biol Chem 280(6): 4307-4312.

Cheng, C. W., Chou, C. C., Hsieh, H. W., Tu, Z., Lin, C. H., Nycholat, C., Fukuda, M. and Khoo, K. H. (2015). Efficient mapping of sulfated glycotopes by negative ion mode nanoLC-MS/MS-Based sulfoglycomic analysis of permethylated glycans. Anal Chem 87(12): 6380-6388.

Cheng, P. F., Snovida, S., Ho, M. Y., Cheng, C. W., Wu, A. M. and Khoo, K. H. (2013). Increasing the depth of mass spectrometry-based glycomic coverage by additional dimensions of sulfoglycomics and target analysis of permethylated glycans. Anal Bioanal Chem 405(21): 6683-6695.

Dell, A., Reason, A. J., Khoo, K. H., Panico, M., McDowell, R. A. and Morris, H. R. (1994). Mass spectrometry of carbohydrate-containing biopolymers. Methods Enzymol 230: 108-132.

Harvey, D. J. (1993). Quantitative aspects of the matrix-assisted laser desorption mass spectrometry of complex oligosaccharides. Rapid Commun Mass Spectrom 7(7): 614-619.

Hernandez Mir, G., Helin, J., Skarp, K. P., Cummings, R. D., Makitie, A., Renkonen, R. and Leppanen, A. (2009). Glycoforms of human endothelial CD34 that bind L-selectin carry sulfated sialyl Lewis x capped Oand N-glycans. Blood 114(3): 733-741.

Hsiao, C. T., Wang, P. W., Chang, H. C., Chen, Y. Y., Wang, S. H., Chern, Y. and Khoo, K. H. (2017). Advancing a high throughput glycotope-centric glycomics workflow based on nanoLC-MS(2)-product dependent-MS(3) analysis of permethylated glycans. Mol Cell Proteomics 16(12): 2268-2280.

Ideo, H., Seko, A., Ohkura, T., Matta, K. L. and Yamashita, K. (2002). High-affinity binding of recombinant human galectin-4 to $\mathrm{SO}_{3}{ }^{--}->3 \mathrm{Gal} \beta 1-->3 \mathrm{GalNAc}$ pyranoside. Glycobiology 12(3): 199-208.

Jang-Lee, J., S. J. North, M. Sutton-Smith, D. Goldberg, M. Panico, H. Morris, S. Haslam and A. Dell (2006). Glycomic profiling of cells and tissues by mass spectrometry: fingerprinting and sequencing methodologies. Methods Enzymol 415: 59-86.

Kawashima, H. (2006). Roles of sulfated glycans in lymphocyte homing. Biol Pharm Bull 29(12): 2343-2349.

Khoo, K. H. and Yu, S. Y. (2010). Mass spectrometric analysis of sulfated N- and O-glycans. Methods Enzymol 478: 3-26.

Kumagai, T., Katoh, T., Nix, D. B., Tiemeyer, M. and Aoki, K. (2013). In-gel $\beta$-elimination and aqueous-organic partition for improved O- and sulfoglycomics. Anal Chem 85(18): 8692-8699.

Mitoma, J., Bao, X., Petryanik, B., Schaerli, P., Gauguet, J. M., Yu, S. Y., Kawashima, H., Saito, H., Ohtsubo, K., Marth, J. D., Khoo, K. H., von Andrian, U. H., Lowe, J. B. and Fukuda, M. (2007). Critical functions of Nglycans in L-selectin-mediated lymphocyte homing and recruitment. Nat Immunol 8(4): 409-418.

Morelle, W. and Michalski, J. C. (2007). Analysis of protein glycosylation by mass spectrometry. Nat Protoc 2(7): 1585-1602.

Patnode, M. L., Cheng, C. W., Chou, C. C., Singer, M. S., Elin, M. S., Uchimura, K., Crocker, P. R., Khoo, K. H. and Rosen, S. D. (2013). Galactose 6-O-sulfotransferases are not required for the generation of Siglec-F ligands in leukocytes or lung tissue. J Biol Chem 288(37): 26533-26545.

Patnode, M. L., Yu, S. Y., Cheng, C. W., Ho, M. Y., Tegesjo, L., Sakuma, K., Uchimura, K., Khoo, K. H., Kannagi, R. and Rosen, S. D. (2013). KSGal6ST generates galactose-6-O-sulfate in high endothelial venules but does not contribute to L-selectin-dependent lymphocyte homing. Glycobiology 23(3): 381-394.

Rosen, S. D. (2004). Ligands for L-selectin: homing, inflammation, and beyond. Annu Rev Immunol 22: 129-156.

Shibata, T. K., Matsumura, F., Wang, P., Yu, S., Chou, C. C., Khoo, K. H., Kitayama, K., Akama, T. O., Sugihara, K., Kanayama, N., Kojima-Aikawa, K., Seeberger, P. H., Fukuda, M., Suzuki, A., Aoki, D. and Fukuda, M. N. (2012). Identification of mono- and disulfated N-acetyl-lactosaminyl Oligosaccharide structures as epitopes specifically recognized by humanized monoclonal antibody HMOCC-1 raised against ovarian cancer. $J$ Biol Chem 287(9): 6592-6602.

Wang, S. H., Tsai, C. M., Lin, K. I. and Khoo, K. H. (2013). Advanced mass spectrometry and chemical analyses reveal the presence of terminal disialyl motif on mouse B-cell glycoproteins. Glycobiology 23(6): 677-689.

Cite as: Yu, S. Y. et al. (2020). Permethylation and Microfractionation of Sulfated Glycans for MS Analysis. Bio-protocol 
Yu, S. Y., Chang, L. Y., Cheng, C. W., Chou, C. C., Fukuda, M. N. and Khoo, K. H. (2013). Priming mass spectrometry-based sulfoglycomic mapping for identification of terminal sulfated lacdiNAc glycotope. Glycoconj J 30(2): 183-194.

Yu, S. Y., Hsiao, C. T., Izawa, M., Yusa, A., Ishida, H., Nakamura, S., Yagi, H., Kannagi, R. and Khoo, K. H. (2018). Distinct substrate specificities of human GlcNAc-6-sulfotransferases revealed by mass spectrometry-based sulfoglycomic analysis. J Biol Chem 293(39): 15163-15177.

Yu, S. Y., Wu, S. W., Hsiao, H. H. and Khoo, K. H. (2009). Enabling techniques and strategic workflow for sulfoglycomics based on mass spectrometry mapping and sequencing of permethylated sulfated glycans. Glycobiology 19(10): 1136-1149.

Yu, S. Y., Cheng, C. W. and Khoo, K. H. (2020). Negative Ion Mode nanoLC-ESI-MS/MS Analyses of Permethylated Sulfated Glycans. Bio-protocol 10(10): e3618. 